\title{
Maternal height associated with cesarean section. A cross-sectional study using the 2014-2015 national maternal-child health survey in Guatemala
}

\author{
Evelyn Roldán *iD, Laura M Grajeda and Wilton Pérez
}

\begin{abstract}
Background: Socioeconomic status is associated with cesarean section (CS). Maternal height, however, may be another related factor to CS. In Guatemala, a quarter of women between 15 and 49 years of age are shorter than $145 \mathrm{~cm}$. Therefore, this study aims to examine the association of maternal height with cesarean section in Guatemala.

Methods: We carried out a secondary analysis study using data from the 2014-15 Guatemalan national maternal and child health survey -9542 mothers aged 15-49 and 12,426 live births were analyzed. We obtained the prevalence ratio of the association between maternal height and CS based on three Poisson regression models. One model included all live births, another the first live birth, and a third model the last live birth. For each model, we accounted for covariates and sampling design.

Results: The national prevalence of CS was $26.3 \%$ (95\%Cl: 25.0, 27.7). The adjusted prevalence ratio of CS, including all live births, was $1.63(95 \% \mathrm{Cl}: 1.37,1.94)$ more likely in mothers shorter than $145 \mathrm{~cm}$ compared with those equal or greater than $170 \mathrm{~cm}$. This figure was $1.45(95 \% \mathrm{Cl}: 1.19,1.76)$ in the model with the first live birth. In the model with the last birth, maternal height was not associated with CS after accounting for previous CS as one of the covariates.

Conclusions: Prevalence of CS in this setting was high and above international recommendations. Further, very short mothers were more likely to experience CS compared to taller mothers after accounting for covariates, except when a previous CS was present. Maternal height should be included in clinical assessments during prenatal care.
\end{abstract}

Keywords: Body height, Mothers, Cesarean section, Health surveys, Guatemala

\section{Background}

Global health policy focuses on measurable improvements in maternal-child health outcomes. The past millennium development goals 1990-2015, for instance, included maternal mortality as a target. Subsequently, the sustainable development goals (SDG) suggested reducing the mortality rate to less than 70 per 100000 live births by 2015-

\footnotetext{
* Correspondence: evelyn.roldan.vernon@gmail.com Universidad del Valle de Guatemala, 18 Avenida 11-95 Zona 15 Vista Hermosa III, 01015 Guatemala, Guatemala
}

2030 -implying an average annual decline of at least $7.5 \%$ [1]. However, in low- and middle- income countries (LMIC), attaining the SDG 3.1 is a challenge. In Guatemala, for example, the maternal mortality ratio decreased from 205 to 88 per 100000 live births, resulting in an average annual decline of 3.5\% during 1990-2015 [1, 2]. Achieving universal and equitable coverage of lifesaving interventions is imperative to improve maternal health and meet the SDG 3.1 [2]. In that regard, a properly indicated cesarean section (CS) is a maternal and offspring

(c) The Author(s). 2020 Open Access This article is licensed under a Creative Commons Attribution 4.0 International License, which permits use, sharing, adaptation, distribution and reproduction in any medium or format, as long as you give appropriate credit to the original author(s) and the source, provide a link to the Creative Commons licence, and indicate if changes were made. The images or other third party material in this article are included in the article's Creative Commons licence, unless indicated otherwise in a credit line to the material. If material is not included in the article's Creative Commons licence and your intended use is not permitted by statutory regulation or exceeds the permitted use, you will need to obtain permission directly from the copyright holder. To view a copy of this licence, visit http://creativecommons.org/licenses/by/4.0/. The Creative Commons Public Domain Dedication waiver (http://creativecommons.org/publicdomain/zero/1.0/) applies to the data made available in this article, unless otherwise stated in a credit line to the data. 
life-saving intervention implemented in most settings [3]. An ecological study -among 172 WHO member statesfound an inverse correlation between country-level prevalence CS in live births and maternal and neonatal mortality [4].

The World Health Organization (WHO) recommends a prevalence of CS between 10 and 15\% [5]. Although a low prevalence $(<10 \%)$ suggests inadequate access to this surgical procedure, a high prevalence $(>19 \%)$ has not shown improvements in perinatal outcomes [4]. A high prevalence of CS may indicate an overuse, and it is associated with adverse health effects for the mother and offspring $[6,7]$-especially in settings with poor quality health care facilities [8].

In LMIC, the use of CS is growing and surpassing the WHO recommendation [5]. In a multicountry study, $18.6 \%$ of live births were by CS [9]. What is more, the global average rate of CS rose from 6.7 to $19.1 \%$ with an annual rate of increase of 4.4\% between 1990 and 2014, where the Latin America and the Caribbean region registered highest absolute rate (19.4\%) [9].

Previous studies reported medical and socioeconomic factors associated with CS. The medical factors may be determined by maternal, obstetric and fetal categories [8-10]. However, non-medical factors may be associated to CS. For instance, studies have found an association between increasing CS rate and socio-economic status $[10,11]$ and cultural factors $[12,13]$. Another understudied determinant in LMIC associated with CS is maternal height. Previous research has shown an association between short maternal height and adverse health effects at the time of delivery through labor complications [14-16]. Further, maternal height has been studied as an indicator of economic status and health [17-19]. Shorter women are more likely to experience poverty and social inequalities in access to health care throughout life than taller women [17]. Noteworthily, lower adult height has indicated poor nutritional and social childhood living conditions [20].

A few studies in European and African settings have analyzed the association between maternal height and CS $[21,22]$. However, to the best of our knowledge, in Latin America, limited evidence exists on the study of maternal height and cesarean section in a large representative sample. In Guatemala, the mean women's height is $149.4 \mathrm{~cm}$, the lowest figure worldwide, which contrasts to that reported in countries with taller women $(168 \mathrm{~cm}$ mean) [23]. Therefore, we conducted secondary data analysis to examine the independent association between CS in live births and maternal height accounted for socioeconomic factors.

\section{Methods}

\section{Study population and design}

This study is a secondary data analysis based on a crosssectional design. Data were gathered through the national demographic health survey (DHS) named VI Maternal and Child Survey of Guatemala 2014-2015 (http://www.dhsprogram.com/). The study population were women from 15 to 49 years of age who gave live births in the last 5 years before the survey. The participation rate was $97 \%$. The analytical dataset of this study was constituted of 9542 mothers with complete information on height and type of delivery, which resulted in 12426 live births (Fig. 1).

The sampling procedure is described elsewhere [24]. In brief, the survey used a stratified, two-stage cluster design. In the first stage, clusters were systematically selected with probability proportional to size. Then, in the second stage, households were systematically randomly selected. Each cluster had a mean of 26 households. All women aged 15-49 were interviewed in the selected household.

\section{Measurements}

The 2014-2015 Guatemala DHS measured maternal height in centimeters. To ensure the quality of the body height measurements, trained examiners were standardized using the Habicht method [24, 25]. We adopted the height cut-offs by Arent and colleagues [21]: very short $(<145.0 \mathrm{~cm})$, short $(145.0-149.9 \mathrm{~cm})$, short-average $(150.0-154.9 \mathrm{~cm})$, average $(155.0-159.9 \mathrm{~cm})$, average-tall $(160.0-169.9 \mathrm{~cm})$ and tall $(\geq 170.0 \mathrm{~cm})$. Type of delivery for each birth was reported by the mother, using the following question: "Was the birth of (name), by cesarean section, that is, did they have to cut your belly to get the baby out? (Yes/No)". For our analysis, the maternal height and CS were the independent and dependent variables, respectively.

We included covariates such as maternal age in years at childbirth $(<19,20-29,30-39,40+)$, ethnicity (indigenous, nonindigenous), maternal education (no education, primary, secondary, higher), place of residence (urban, rural), prenatal visits $(<4,4+)$, place of birth (public, private, home), skilled birth attendant (yes, no), multiple birth (yes, no), birth order $(1,2-3,4+)$, and previous CS (yes, no). The Guatemala DHS computed household wealth index applying principal component analysis (PCA) on all household assets (e.g., TV, radio, mobile) and housing conditions (e.g., type of water, sanitation, wall, floor). Then, the Guatemala DHS categorized the household wealth index in quintiles as poorest, poorer, middle, richer and richest. 


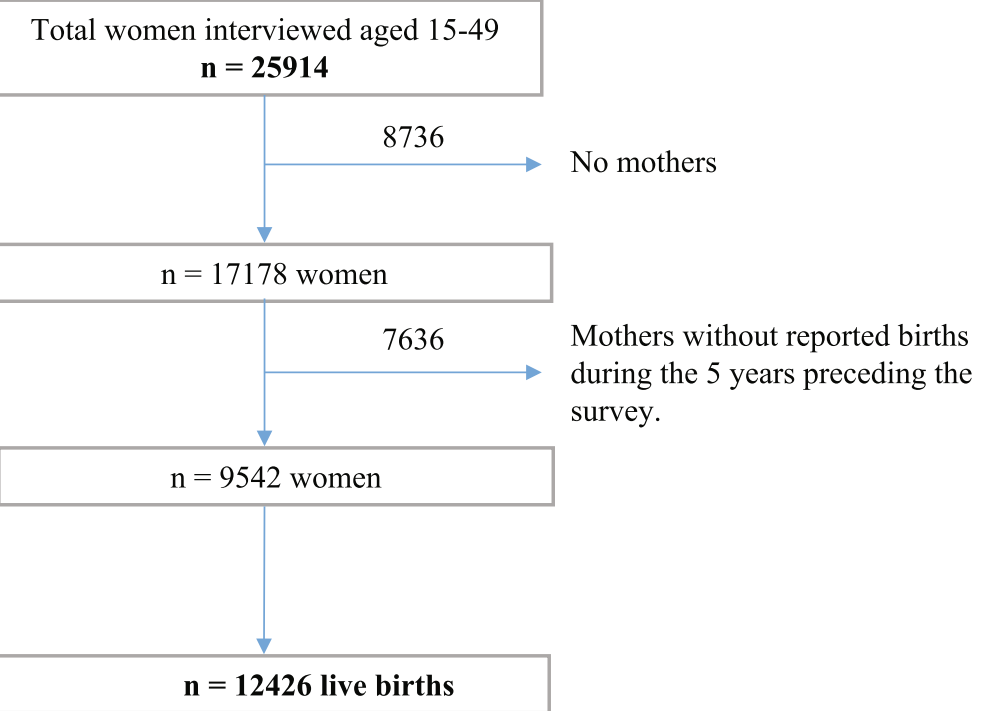

Fig. 1 Flow chart of observations used for the analysis, Guatemala 2014-2015

\section{Data analysis}

We calculated the prevalence of CS with its respective 95\% confidence interval. To assess the association between maternal height and CS, we conducted multivariable Poisson regression models. The Poisson model allowed obtaining the adjusted prevalence ratio, recommended for binary outcomes with a prevalence greater than $10 \%$ [26]. Three Poisson models were analyzed. The first model included all live births, the second model included the first live birth and the third model the last live birth. We added a covariate into the regression model when the bivariate association with CS showed a $p$-value $<0.2$ in the chi-square test [27]. We assessed the interaction between maternal height and covariates in each model using the "testparm" command. To facilitate interpretation, we dichotomized the maternal height $(<145 \mathrm{~cm}, \leq 145 \mathrm{~cm})$ for the interaction analysis. We found significant interaction $(p$-value $<0.05)$ with ethnicity for the model that included the first live birth. We reported the prevalence ratio, with its respective $95 \%$ confidence interval in the models. We did not include the place of birth in the first model as CS was not reported in at home births. A $p$-value $<0.05$ was significant. The "svyset" commands were used to account for the complex sampling design. We found no evidence of multicollinearity in all models $(\mathrm{VIF}<10)$. The analysis was done in Stata 14.2 (Stata Corporation, College Station, TX).

\section{Ethical considerations}

This study was a secondary data analysis using public dataset (www.dhsmeasure.com). We obtained consent from The DHS Program to use the dataset. Furthermore, we obtained ethical approval by the Institutional Review Boards at Universidad del Valle in Guatemala with the reference number 188-01-2019. Finally, for this analysis, the dataset is anonymous.

\section{Results}

Figure 2 shows the distribution of maternal height categories. The mean (standard deviation) maternal height was $148.8 \mathrm{~cm}$ (6.17), and $25.4 \%$ were shorter than 145 $\mathrm{cm}$. Table 1 shows that $58.7 \%$ of the deliveries occurred in mothers aged $20-29$ and $51.3 \%$ in nonindigenous mothers. In half of the births, mothers had only primary education, and half the mothers were in the first (poorest) or second (poorer) wealth index quintile. Almost, two-thirds of live births were in rural areas, and $15.6 \%$ were home deliveries. Skilled birth personnel attended $65.4 \%$ deliveries, $85 \%$ of births had four or more prenatal visits, and $18.3 \%$ of mothers reported a previous CS.

\section{Maternal and cesarean section association}

The national prevalence of CS was 26.3\% (95\%CI: 25.0, 27.7). Among the first births and last births, the prevalence of CS was 36.1 (95\%CI: 34.2, 38.0) and 29.3 (95\%CI: $27.9,30.6)$ respectively. All covariates were associated with CS with a $p$-value $<0.2$, and therefore considered for the modeling (Table 2). Table 2 shows the adjusted prevalence ratio (aPR) for the three models. For model 1 (all live births), the aPR of CS was 1.63 (95\%CI: $1.37,1.94)$ in very short mothers $(<145 \mathrm{~cm})$ compared to taller $(\geq 170 \mathrm{~cm})$. In model 2 (first birth) this figure was 1.45 (95\%CI: 1.19, 1.76), and in model 3 for the last birth, this association was not significant after accounting for previous CS which had an aPR of 11.75 (95\%CI: 


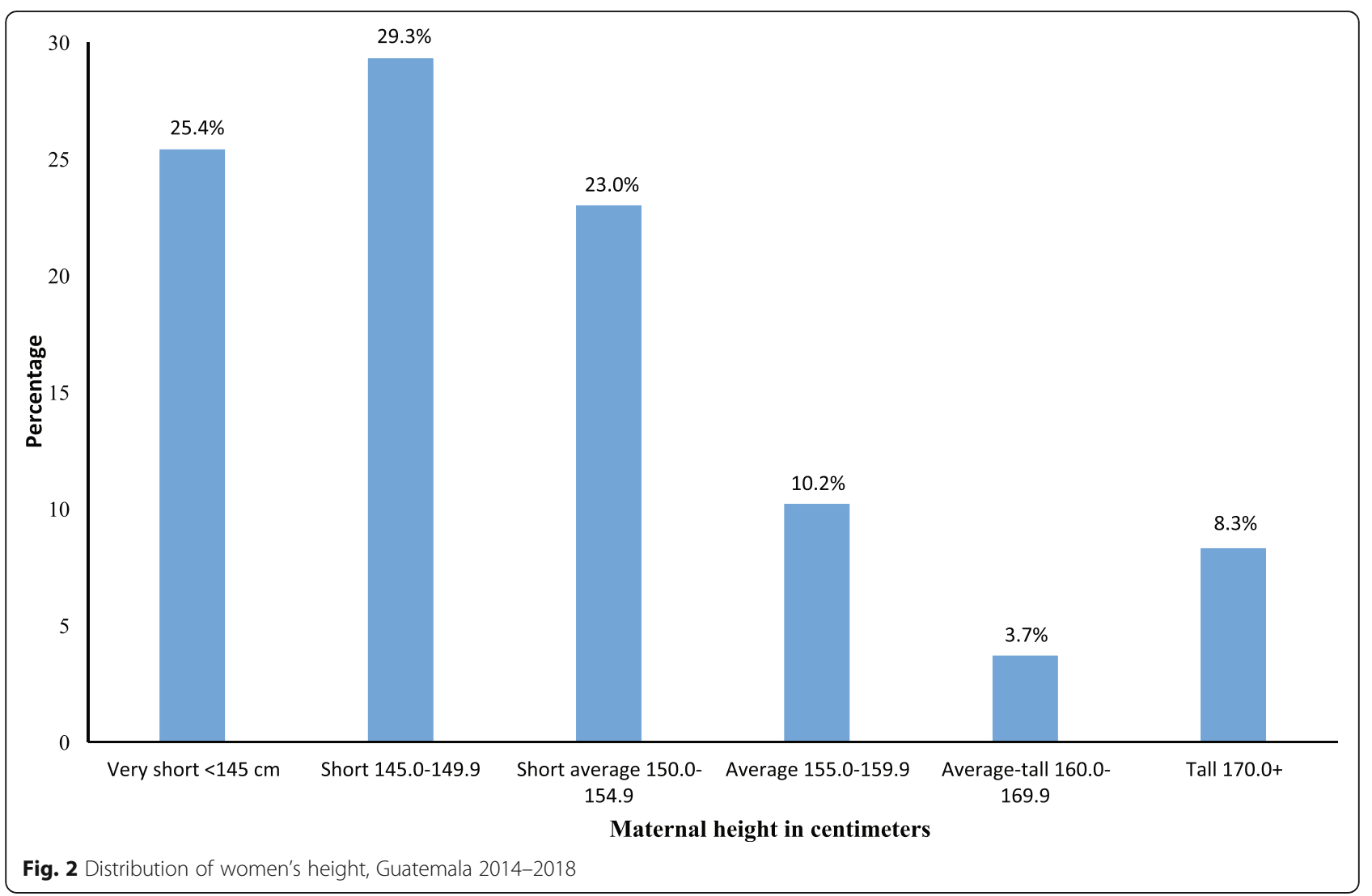

9.93, 13.91). Table 3 shows the interaction analysis in all first live birth. The aPR was significantly higher among shorter mothers $(<145 \mathrm{~cm})$ than taller $(\geq 145 \mathrm{~cm})$ in indigenous and nonindigenous. Taller indigenous were less likely to experience cesarean section than taller nonindigenous.

In both model 1 and model 2, mothers over 30 were more likely to have a CS compared to the other younger age groups of mothers. However, in the model with the last birth, CS was significantly higher in mothers aged 30-39 compared to mothers under 19. By socioeconomic status, CS was most likely in mothers in the richest quintile compared to those in the poorest quintile. Regarding ethnicity, indigenous mothers had less chance than nonindigenous of CS, although, in model 2, it was not significant. In the model of all live births, multiple births had 2.7 more chance of CS than single births. Those births of higher-order were more likely to experience a CS compared to a birth of first order. (Additional File 1).

\section{Discussion}

This large representative national study included live birth deliveries from mothers of reproductive age, examined the frequency of cesarean sections and its relationship with maternal height. We found a prevalence of cesarean section above the WHO recommendation. Lower maternal height independently associated to cesarean section, except when the model accounted for previous cesarean delivery.

Our findings show that the prevalence of CS is increasing in Guatemala. In 2002, the national prevalence of CS was $11.2 \%$, less than half of the reported in this study (26.3\%) [24]. This finding is in line with previous studies from low-income settings where vaginal delivery is becoming a less utilized mode of delivery and CS is becoming more common [28]. Notably, the evidence has shown no further health benefits for the mother and offspring with a prevalence of CS above $19 \%$, and thus, overuse of this surgery may be occurring [4]. A Guatemalan study carried out from 2010 to 2016 included more 30000 deliveries and reported that out of the $18 \%$ CS only $10 \%$ were for lifesaving indications [29].

The association between maternal height and CS analyzing all live births and the first birth was consistent with the findings of a study in sub-Saharan Africa settings, where mothers whose height was less than $145 \mathrm{~cm}$ had twice the probability of CS compared to mothers with a height of $145 \mathrm{~cm}$ or above [21]. An explanation is that maternal height may represent an obstetric risk during delivery. Mothers of 
Table 1 Background characteristics of mothers and bivariate association between covariates and CS, Guatemala 2014-2015

\begin{tabular}{llll}
\hline Characteristics & $\begin{array}{l}\text { Number of deliveries } \\
n=12426\end{array}$ & Percentage of deliveries & Preval \\
\hline $\begin{array}{llll}\text { Age at birth (years) } \\
<19\end{array}$ & 1853 & 14.9 & 24.2 \\
$20-29$ & 7294 & 58.7 & 27.9 \\
$30-39$ & 2926 & 23.6 & 24.9 \\
$40+$ & 353 & 2.8 & 15.7
\end{tabular}

\section{Ethnicity}

Nonindigenous
Indigenous
Missing
Maternal education

$\begin{array}{ll}\text { No education } & 2291 \\ \text { Primary } & 6573 \\ \text { Secondary } & 3077 \\ \text { Higher } & 485\end{array}$

Wealth index quintile

Poorest

Poorer

Middle

Richer

Richest

Residence

$\begin{array}{ll}\text { Rural } & 8158 \\ \text { Urban } & 4268\end{array}$

Prenatal visits

$$
\begin{aligned}
& <\text { or more } \\
& 4 \text { is }
\end{aligned}
$$

Missing

\section{Place of birth}

$\begin{array}{ll}\text { Public } & 6187 \\ \text { Private } & 4241 \\ \text { Home } & 1940 \\ \text { Missing } & 58\end{array}$

Skilled birth attendant
No

Yes

$$
\text { No }
$$

Yes

Birth order

$\begin{array}{ll}1 & 3972 \\ 2-3 & 5011 \\ 4+ & 3443\end{array}$

4301

8125

12209
Multiple births
6371

6051

3394

2857

2472

2142

1561

51.3

48.7

0.0

18.4

52.9

24.8

3.9

27.3

23.0

19.9

17.2

12.6

65.7

34.4

15.0

85.0

0.0

49.8

34.1

15.6

0.5

98.3

1.8

32.0

40.3

27.7
Prevalence of CS (\%)

p-value

24.2

$<0.001$

27.9

24.9

15.7

35.5

$<0.001$

17.9

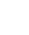

9

21.2

43.0

66.7

Previous cesarean section for the last reported birth $n=2597$ 
Table 1 Background characteristics of mothers and bivariate association between covariates and CS, Guatemala 2014-2015 (Continued)

\begin{tabular}{llll}
\hline Characteristics & Number of deliveries & Percentage of deliveries & Prevalence of CS (\%) \\
& $n=12426$ & & \\
\hline No & 2121 & 81.7 & 7.6 \\
Yes & 476 & 18.3 & 89.3 \\
\hline
\end{tabular}

very short $(<145 \mathrm{~cm})$ stature have elevated risk of labor obstruction attributable to cephalopelvic disproportion [14-16, 30].

Another potential factor that contributes to the association between short maternal stature and cesarean is the nutritional status. In Brazil, shorter women were more likely to be overweight or obese than those taller [19], and excess weight has been found to increase CS [31]. Furthermore, a systematic review showed increased odds of newborns with large size for gestational age, higher birth weight and macrosomia in offspring whose mothers were overweight/obese before pregnancy than in those whose mothers' weight was normal [32]. Thus, overweight and obesity previous to or during pregnancy in short/very short mothers may prolong labor and therefore indicate a CS [33]. The former has public health implications in Guatemala as overweight and obesity in 2014 affected $85 \%$ of women aged 15-49 [34] and half of the non-pregnant women with the intention to conceive [35].

Maternal height has been studied as a socioeconomic indicator for social and health inequalities [20]. Short mothers are more likely to experience barriers to access to high-quality health care services [36]. In our study sample, the percentage of very short mothers $(<145 \mathrm{~cm})$ was higher in rural, primary/noneducated, poorer/poorest and indigenous compared to their counterparts (Additional file 2). The lower socioeconomic position of women reduces access to health and reproductive health-seeking behavior [36, 37]. Therefore, mothers with short/very short height may have experienced socioeconomic, physical and cultural barriers to access to delivery facilities. The delay for seeking healthcare may motivate medical staff to recommend a CS to prevent adverse maternal and offspring outcomes during labor [37]. However, further studies are needed to document the extent of the association between healthcare-seeking delay for delivery and CS.

For the last birth model, after accounting for previous CS, the association between maternal height and CS was not significant. In our study, $68.4 \%$ of CS (data not shown) reported in the most recent singleton birth were performed on mothers who had had a previous cesarean delivery. The lack of association reported in this study was not a surprise, as, in many settings, CS is indicated when the mother has had a previous CS [38, 39].

We found $15.6 \%$ of births were home deliveries. Among these deliveries, $36.9 \%$ were from very short mothers, as compared to $10.6 \%$ in taller mothers. Further, a higher proportion of mothers were indigenous (75.0\%) in this group of home deliveries. According to a 2013 survey by Salud Mesoamerica Initiative (SMI), Guatemalan indigenous women were less likely to have an institutional delivery compared to nonindigenous [40]. SMI also found that partial and complete prenatal care was associated with higher odds of in-facility delivery compared to those who did not receive any prenatal care [41]. We found that complete prenatal care (4 or more visits) was higher in taller mothers compared to very short-although it was not significant (Additional file 2). Therefore, further research is needed to analyze the social circumstances experienced by very short mothers delivering at home and the health maternal and offspring outcomes.

\section{Strengths and limitations}

This study has strengths and limitations. One strength is the large sample with national representation. The participation rate was $97 \%$, which reduces the potential for selection bias. The proportion of missing information was very low $(<0.5 \%)$.

There is a potential to recall bias in terms of selfreporting of CS as reported elsewhere [42]. We try to overcome this issue by constraining our analysis using the first and last birth. There are several variables related to CS not collected during the survey due to the crosssectional design. For instance, gestational age at the time of delivery, information regarding whether the CS was an elective or emergency procedure, maternal nutrition during pregnancy (e.g., obesity), onset of labor, cephalic circumference and fetal presentation. As we used the data from a cross-sectional survey, we only reported the association between maternal height and CS without assuming a causal relationship.

\section{Conclusions}

In Guatemala, the prevalence of CS deliveries is high and above international recommendations. Besides, CS was used more frequently in very short mothers. However, this association lost significance when previous CS 


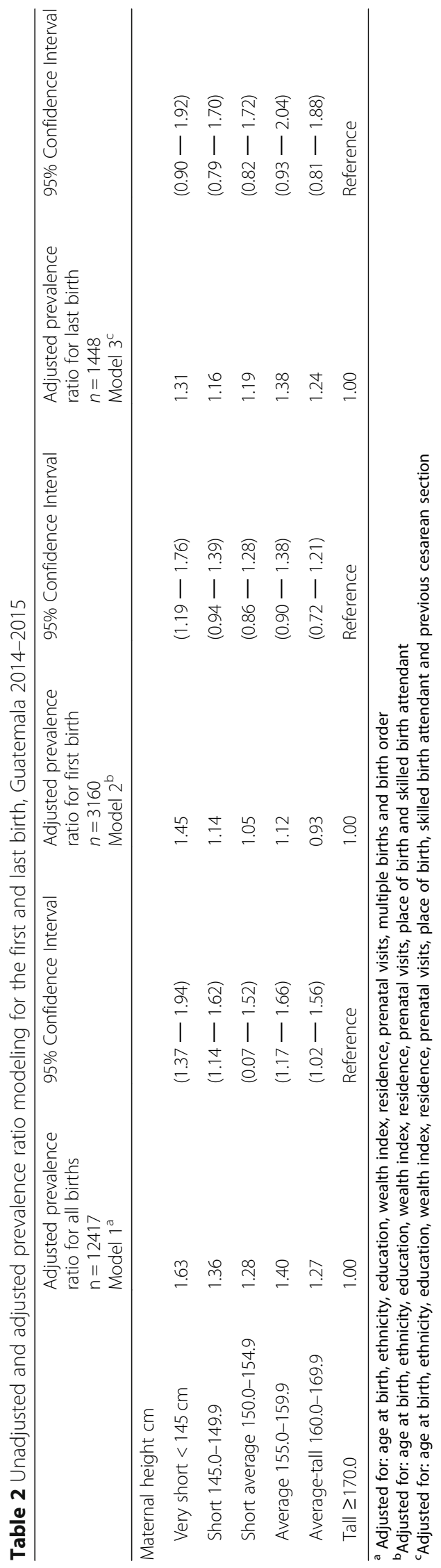


Table 3 Cesarean section prevalence ratio in relation to ethnicity and maternal height for the first live birth, Guatemala 2014-2015

\begin{tabular}{llll}
\hline Ethnicity & Maternal height cm & Adjusted prevalence ratio ${ }^{a}$ & $\begin{array}{l}95 \% \\
\text { Confidence interval }^{p}\end{array}$ \\
\hline Nonindigenous & $<145$ & 1.19 & $(1.02-1.38)$ \\
& $\geq 145$ & 1.00 & Reference \\
Indigenous & $<145$ & 1.29 & $(1.14-1.47)$ \\
& $\geq 145$ & 0.87 & $(0.77-0.98)$ \\
\hline
\end{tabular}

${ }^{\mathrm{a}}$ Adjusted for: age at birth, education, wealth index, residence, prenatal visits, place of birth and skilled birth attendant

was accounted for. One implication from our findings is that the health system needs to explore the reasons for this association and the social circumstances experienced by the mother.

Furthermore, our study findings reinforce -indirectlythe importance of implementing comprehensive and cost-effective health and nutrition intervention policies as short adult height represents the accumulated effect of social, health and nutrition deprivations across generations [43-46].

\section{Supplementary information}

Supplementary information accompanies this paper at https://doi.org/10. 1186/s12939-020-01182-8.

Additional file 1. Adjusted prevalence ratio for the three models.

Additional file 2. Live birth distribution by maternal height and social and obstetric characteristics.

\section{Abbreviations}

95\% Cl: 95\% confidence interval; CS: Cesarean Section; DHS: Demographic Health Survey; LMIC: Low- and middle-income countries; SDG: Sustainable Development Goals; SMI: Salud Mesoamerica Initiative; VIF: Variance inflation factor; WHO: World Health Organization

\section{Acknowledgements}

We thank The DHS Program for granting us access to analyze data on maternal and child health in Guatemala.

\section{Authors' contributions}

WP conceived the article. ER prepared the initial draft of the manuscript and carried out the statistical analyses. WP and LG interpreted and edited. The authors read and approved the manuscript.

\section{Funding}

This study was not funded.

\section{Availability of data and materials}

Requests for the data must be made to The DHS Program at https:// dhsprogram.com.

\section{Ethics approval and consent to participate}

The secondary data analysis received ethical approval from the Institutional Review Boards at Universidad del Valle in Guatemala with reference number 188-01-2019. Procedures and questionnaires for standard DHS surveys were reviewed and approved by the ICF Institutional Review Board (IRB).

Additionally, country-specific DHS survey protocols were reviewed by the ICF IRB and typically by an IRB in the host country.

\section{Consent for publication}

Not applicable.

\section{Competing interests}

The authors declare that they have no competing interests.

Received: 4 December 2019 Accepted: 29 April 2020

Published online: 31 July 2020

\section{References}

1. Alkema L, Chou D, Hogan D, Zhang S, Moller A-B, Gemmill A, et al. Global, regional, and national levels and trends in maternal mortality between 1990 and 2015, with scenario-based projections to 2030: a systematic analysis by the UN maternal mortality estimation inter-agency group. Lancet. 2016;387: 462-74.

2. Organization WH, UNICEF, Nations $U$, Affairs D of E and S, Division P, Bank W. Trends in maternal mortality: 1990 to 2015 estimates by WHO, UNICEF, UNFPA, World Bank Group and the United Nations population division; 2015. http://www.who.int/reproductivehealth/publications/monitoring/ maternal-mortality-2015/en/. Accessed 19 Jul 2019.

3. Sandall J, Tribe RM, Avery L, Mola G, Visser GHA, Homer CSE, et al. Shortterm and long-term effects of caesarean section on the health of women and children. Lancet. 2018;392:1349-57.

4. Molina G, Weiser TG, Lipsitz SR, Esquivel MM, Uribe-Leitz T, Azad T, et al. Relationship between cesarean delivery rate and maternal and neonatal mortality. JAMA. 2015;314:2263-70.

5. Betran A, Torloni M, Zhang J, Gülmezoglu A. Section the WHOWG on C. WHO statement on caesarean section rates. BJOG An Int J Obstet Gynaecol. 2016;123:667-70.

6. Fahmy WM, Crispim CA, Cliffe S. Association between maternal death and cesarean section in Latin America: a systematic literature review. Midwifery. 2018;59:88-93.

7. Althabe F, Sosa C, Belizán JM, Gibbons L, Jacquerioz F, Bergel E. Cesarean section rates and maternal and neonatal mortality in low-, medium-, and high-income countries: an ecological study. Birth. 2006;33:270-7.

8. Merchant KM, Villar J, Kestler E. Maternal height and newborn size relative to risk of intrapartum caesarean delivery and perinatal distress. BJOG. 2001; 108:689-96.

9. Betrán AP, Ye J, Moller A-B, Zhang J, Gülmezoglu AM, Torloni MR. The increasing trend in caesarean section rates: global, regional and National Estimates: 1990-2014. PLoS One. 2016;11:e0148343.

10. Potter JE, Berquo E, Perpetuo IHO, Leal OF, Hopkins K, Souza MR, et al. Unwanted caesarean sections among public and private patients in Brazil: prospective study. BMJ. 2001;323:1155-8.

11. Boerma T, Ronsmans C, Melesse DY, Barros AJD, Barros FC, Juan L, et al. Global epidemiology of use of and disparities in caesarean sections. Lancet. 2018:392:1341-8.

12. Karlström A, Nystedt A, Johansson M, Hildingsson I. Behind the myth - few women prefer caesarean section in the absence of medical or obstetrical factors. Midwifery. 2011;27:620-7.

13. Behague DP. Consumer demand for caesarean sections in Brazil: informed decision making, patient choice, or social inequality? A population based birth cohort study linking ethnographic and epidemiological methods. BMJ. 2002;324:942

14. Sheiner E, Levy A, Katz M, Mazor M. Short stature - an independent risk factor for cesarean delivery. Eur J Obstet Gynecol Reprod Biol. 2005;120:175-8.

15. Kara F, Yesildaglar N, Uygur D. Maternal height as a risk factor for caesarean section. Arch Gynecol Obstet. 2005;271:336-7.

16. McGuinness BJ, Trivedi AN. Maternal height as a risk factor for caesarean section due to failure to progress in labour. Aust N Z J Obstet Gynaecol. 1999;39:152-4. 
17. Bogin B, Scheffler C, Hermanussen M. Global effects of income and income inequality on adult height and sexual dimorphism in height. Am J Hum Biol. 2017;29:e22980.

18. Castro-Porras LV, Rojas-Russell ME, Aedo-Santos Á, Wynne-Bannister EG, López-Cervantes M. Stature in adults as an indicator of socioeconomic inequalities in Mexico. Rev Panam Salud Publica. 2018:42:e29.

19. Álvarez LS, Estrada A, Goez JD, Carreño C, Mancilla LP. The effects of socioeconomic status and short stature on overweight, obesity and the risk of metabolic complications in adults. Colomb Med. 2013;44:146-54.

20. Subramanian SV, Özaltin E, Finlay JE. Height of nations: a socioeconomic analysis of cohort differences and patterns among women in 54 low- to middle-income countries. PLoS One. 2011;6:e18962.

21. Arendt E, Singh NS, Campbell OMR. Effect of maternal height on caesarean section and neonatal mortality rates in sub-Saharan Africa: an analysis of 34 national datasets. PLoS One. 2018;13:e0192167.

22. Mogren I, Lindqvist M, Petersson K, Nilses C, Small R, Granåsen G, et al. Maternal height and risk of caesarean section in singleton births in Sweden-a population-based study using data from the swedish pregnancy register 2011 to 2016. PLoS One. 2018;13:e0198124.

23. NCD Risk Factor Collaboration. A century of trends in adult human height: 2016. https://doi.org/10.7554/eLife.13410.

24. MSPAS. VI Encuesta Nacional de Salud Materno Infantil 2014-2015 (ENSMI); 2014. https://www.ine.gob.gt/images/2017/encuestas/ensmi2014_2015.pdf. Accessed 10 Oct 2018.

25. Habitcht JP. Standardization of quantitative epidemiological methods in the field. Reimpreso del Boletin de la Oficina Sanitaria Panamericana. 1974 http://iris.paho.org/xmlui/handle/123456789/10766. Accessed 18 Jul 2019.

26. Martinez BAF, Leotti VB, de S e SG, Nunes LN, Machado G, Corbellini LG. Odds ratio or prevalence ratio? An overview of reported statistical methods and appropriateness of interpretations in cross-sectional studies with dichotomous outcomes in veterinary medicine. Front Vet Sci. 2017:4:193.

27. Maldonado G, Greenland S. Simulation study of confounder-selection strategies. Am J Epidemiol. 1993;138:923-36.

28. Harrison MS, Pasha O, Saleem S, Ali S, Chomba E, Carlo WA, et al. A prospective study of maternal, fetal and neonatal outcomes in the setting of cesarean section in low- and middle-income countries. Acta Obstet Gynecol Scand. 2017;96:410-20.

29. Belizán JM, Minckas N, McClure EM, Saleem S, Moore JL, Goudar SS, et al. An approach to identify a minimum and rational proportion of caesarean sections in resource-poor settings: a global network study. Lancet Glob Health. 2018;6:e894-901.

30. Bohlmann MK, Luedders DW, Beyer D, Kavallaris A, Baumann K, Diedrich K, et al. Nulliparous patients with small stature delivering at term have an increased risk of secondary cesarean section. Arch Gynecol Obstet. 2010;282: 241-4.

31. Poobalan AS, Aucott LS, Gurung T, Smith WCS, Bhattacharya S. Obesity as an independent risk factor for elective and emergency caesarean delivery in nulliparous women - systematic review and meta-analysis of cohort studies. Obes Rev. 2009;10:28-35.

32. Yu Z, Han S, Zhu J, Sun X, Ji C, Guo X. Pre-pregnancy body mass index in relation to infant birth weight and offspring overweight/obesity: a systematic review and meta-analysis. PLoS One. 2013;8:e61627.

33. Chu SY, Kim SY, Schmid CH, Dietz PM, Callaghan WM, Lau J, et al. Maternal obesity and risk of cesarean delivery: a meta-analysis. Obes Rev. 2007:8:38594

34. Mazariegos M, Kroker-Lobos MF, Ramírez-Zea M. Socio-economic and ethnic disparities of malnutrition in all its forms in Guatemala. Public Health Nutr. 2019. https://doi.org/10.1017/S1368980019002738.

35. Hambidge KM, Krebs NF, Garcés A, Westcott JE, Figueroa L, Goudar SS, et al. Anthropometric indices for non-pregnant women of childbearing age differ widely among four low-middle income populations. BMC Public Health. 2018;18:45.

36. Ishida K, Stupp P, Turcios-Ruiz R, William DB, Espinoza E. Ethnic inequality in Guatemalan Women's use of modern reproductive health care. Int Perspect Sex Reprod Health. 2012;38:99-108

37. Akter S, Davies K, Rich JL, Inder KJ. Indigenous women's access to maternal healthcare services in lower- and middle-income countries: a systematic integrative review. Int J Public Health. 2019;64:343-53.

38. Getahun D, Oyelese Y, Salihu HM, Ananth CV. Previous cesarean delivery and risks of placenta Previa and placental abruption. Obstet Gynecol. 2006; 107:771-8.
39. Ananth CV, Smulian JC, Vintzileos AM. The association of placenta previa with history of cesarean delivery and abortion: a metaanalysis. Am J Obstet Gynecol. 1997;177:1071-8.

40. Colombara DV, Hernández B, Schaefer A, Zyznieuski N, Bryant MF, Desai SS, et al. Institutional delivery and satisfaction among indigenous and poor women in Guatemala, Mexico, and Panama. PLoS One. 2016;11:e0154388.

41. McNellan CR, Dansereau E, Wallace MCG, Colombara DV, Palmisano EB, Johanns CK, et al. Antenatal care as a means to increase participation in the continuum of maternal and child healthcare: an analysis of the poorest regions of four Mesoamérican countries. BMC Pregnancy Childbirth. 2019;19: 66.

42. Stanton CK, Dubourg D, De Brouwere V, Pujades M, Ronsmans C. Reliability of data on caesarean sections in developing countries. Bull World Health Organ. 2005;83:449-55

43. Stein AD, Barnhart HX, Wang M, Hoshen MB, Ologoudou K, Ramakrishnan U, et al. Comparison of linear growth patterns in the first three years of life across two generations in Guatemala. Pediatrics. 2004;113:e270-5.

44. Imdad A, Sadiq K, Bhutta ZA. Evidence-based prevention of childhood malnutrition. Curr Opin Clin Nutr Metab Care. 2011;14:276-85.

45. Ramakrishnan U, Martorell R, Schroeder DG, Flores R. Role of intergenerational effects on linear growth. J Nutr. 1999;129:544S-9S.

46. Perkins JM, Subramanian SV, Davey Smith G, Özaltin E. Adult height, nutrition, and population health. Nutr Rev. 2016;74:149-65.

\section{Publisher's Note}

Springer Nature remains neutral with regard to jurisdictional claims in published maps and institutional affiliations.
Ready to submit your research? Choose BMC and benefit from:

- fast, convenient online submission

- thorough peer review by experienced researchers in your field

- rapid publication on acceptance

- support for research data, including large and complex data types

- gold Open Access which fosters wider collaboration and increased citations

- maximum visibility for your research: over $100 \mathrm{M}$ website views per year

At $\mathrm{BMC}$, research is always in progress.

Learn more biomedcentral.com/submissions 